\title{
O DUELO DE RIMAS NO RAP COMO ATIVIDADE DE LAZER DE JOVENS
}

Recebido em: $23 / 05 / 2012$

Aceito em: 22/02/2013

\author{
Daniel Bidia Olmedo Tejera ${ }^{1}$ \\ Carmen Maria Aguiar ${ }^{2}$ \\ Universidade Estadual Paulista "Júlio de Mesquita Filho" \\ Rio Claro - São Paulo - Brasil
}

RESUMO: Este trabalho versará sobre a Batalha Central, evento mensal que acontece no centro de Piracicaba/SP em que admiradores da música Rap se reúnem para travar duelos de rimas de uma forma lúdica. O objetivo deste trabalho é identificar se o Rap no contexto das batalhas de improviso, pode ou não proporcionar ao participante um momento de lazer que possa contribuir para o seu desenvolvimento, principalmente crítico e criativo, além de verificar a influência de ordem moral e cultural que os preceitos do Hip-hop podem exercer em seus participantes. Esta é uma pesquisa qualitativa caracterizada por ser um estudo de caso e exploratório. Através deste estudo, foi possível perceber consideravelmente a influência exercida pelos preceitos do Hiphop na vida dos jovens que participam desta prática, além de entender especificamente como as batalhas de Mc`s interferem no desenvolvimento da criatividade e criticidade do praticante.

PALAVRAS CHAVE: Música. Atividades de Lazer. Adolescente.

\section{THE DUEL OF RHYMES AS LEISURE ACTIVITY OF YOUNG}

ABSTRACT: This paper will focus on the "Batalha Central", an event that happens every month at downtown of Piracicaba / SP in which admirers Rap music come together to fight duels rhymes in a playful way. The objective of this study is to identify if the Rap battles in may or may not provide the participant with a moment of leisure can contribute to its development, especially critical and creative and to check the influence moral and cultural precepts of the Hip-hop can have on participants. This is a qualitative research is characterized by a case study and exploration. Through this study it was possible to understand a little of the influence exerted by the precepts of Hip-hop in the lives of young people participating in this practice, in addition to understanding a little about how specifically the battles of Mc 's interferes with the development of creativity and criticality of the practitioner.

KEYWORDS: Music. Leisure Activities. Adolescent.

\footnotetext{
${ }^{1}$ Mestrando pelo DEF/IB Universidade Estadual Paulista Júlio de Mesquita Filho - Rio Claro/SP - Bolsista CNPq / Integrante do GPL e-mail: olmedo@ig.com.br

2 Professora Doutora do DEF/IB e do Programa de pós-graduação de Ciências da Motricidade da Universidade Estadual Paulista Júlio de Mesquita Filho - Rio Claro/SP e-mail: carmenaguiar@uol.com.br
} 


\section{Introdução}

Registros revelam que em meados do século XVIII, lazer trabalho e meio ambiente não apresentavam uma linha de separação clara entre si. As colheitas eram realizadas simultaneamente com danças, cantos e alegria, o que fazia disso um momento único, sem haver dicotomia entre trabalho e lazer. O tempo era regido por fenômenos da natureza, como estações do ano e o posicionamento do sol (BAHIA, 2005).

Foi a partir do surgimento da sociedade industrial que a fluência da relação entre lazer e trabalho sofreu grandes transformações. A partir desse momento, as pessoas passaram a ter que se deslocar de suas casas para o local de trabalho, - trabalho e moradia passam a não dividir mais o mesmo espaço - extinguindo o trabalho artesanal. O tempo deixa de ser regido pelos fenômenos da natureza e passa ser cadenciado de acordo com o trabalho (BRUHNS ${ }^{3}, 1997$ apud CAPI, 2006, p17).

Segundo Nelson Marcellino (2002), estes e outros fatores levaram os pensadores do século XIX a refletir sobre o lazer. No continente europeu, o trabalho - agora industrial - explorava em demasia os operários, de forma a desrespeitá-los como seres humanos, fato este que propiciou vários manifestos em forma de obra literária, porém somente no início do século XX, nos Estados Unidos e na Europa, foram desenvolvidos estudos do lazer de forma sistemática. Essa sistematização dos estudos do lazer, a partir da década de 50, passou a ser aderida nas sociedades urbanas e industriais de forma geral, tanto nas capitalistas quanto nas socialistas.

Já no Brasil, os estudos da temática só evoluíram 50 anos após a evolução já ocorrida na Europa. O principal motivo deste fato, é que na Europa o interesse por esse

\footnotetext{
${ }^{3}$ BRUHNS, H. T. Relações entre a educação e o lazer. In: BRUHNS, H. T. (Org.). Introdução aos estudos do lazer. Campinas: Ed Unicamp, 1997. p. 33-55.
} 
tipo de estudo se deu devido à industrialização, entretanto no Brasil, o mesmo está relacionado ao processo de urbanização. As universidades brasileiras deram início às pesquisas a partir dos anos 70, que foram se desenvolvendo de forma relevante até a década de 90, período em que surgiram diversas teses sobre o tema, principalmente teses interligadas a produção cultural e a educação (MARCELLINO, 2002).

Pode-se dizer atualmente, que o lazer é um fenômeno advindo da sociedade urbana caracterizado por Nelson Marcellino (2002) como uma esfera social importante na vida moderna para mudanças de ordem moral e cultural.

Embora o principal objetivo das atividades de lazer seja o divertimento e o descanso, é importante que esta prática colabore também para um terceiro item importante do lazer: o desenvolvimento, que pode ser pessoal e social. Juntando divertimento, descanso e desenvolvimento, temos os 3D`s do lazer (MARCELLINO, 2002).

O lazer, além de carregar como características fundamentais o descanso, o divertimento e o desenvolvimento pessoal e social, também é um eficiente veículo promotor de educação. Embora pareça não estabelecer uma relação direta, a educação e o lazer caminham lado a lado, ao passo que, o desfrutar do lazer muitas vezes pode ser decorrente de um determinado processo educacional. O lazer pode vir a ser um privilegiado espaço de crescimento crítico e criativo.

Nesse sentido, vamos abordar uma prática emergida no tempo de lazer, nos subúrbios nova-iorquinos, atualmente presente no mundo todo.

Surgido num contexto de desemprego, crise de industrialização e aumento da violência, o Hip-hop emerge de um contexto urbano, criado por jovens negros e imigrantes caribenhos como uma forma de expressão cultural, o Hip-hop vem à tona 
numa época próxima dos movimentos de contracultura, no distrito do Bronx, Nova Iorque, Estados Unidos na década de 60 (SILVA, 1999).

A fim de transformar a violência das gangues em disputas sadias, Afrika Bambaataa - um dos principais organizadores das festas de rua - passou a organizar tais festas, objetivando converter as "rixas" em duelos que envolviam expressões artísticas divididas em quatros elementos: $M c$ (que faz as rimas), $D j$ (que toca o som), Break (a dança) e Grafite (artes plásticas).

\begin{abstract}
A ideia de Afrika Bambaataa era transformar o negativismo das gangues em energia positiva, pois perdera o melhor amigo em uma guerra das gangues, no tempo que fizera parte de uma gangue. Cansado disso, pensou em fazer algo para mudar esta situação, as pessoas estavam cada vez mais ocupadas com o Hip-Hop, em mostrar suas habilidades da melhor forma possível nas festas. (VENTURA, s.d.).
\end{abstract}

A fusão entre o Mc e o Dj originou o Rap (Rythm and Poetry), em português Ritmo e Poesia (SOUZA e NISTA-PICCOLO, 2006).

O Rap é uma manifestação da linguagem falada incorporada a uma melodia que trabalha uma base rítmica repetitiva. Traz crônicas dos habitantes de um determinado grupo social (ROSA, 2004). Pires (2007), se refere ao Rap como o pilar central do Hiphop, esse estilo musical usa a forma básica de expressão: a voz. Na sua essência original, a voz permanece praticamente numa mesma nota. Originário do canto falado da África ocidental, o rap foi adaptado à música jamaicana da década de 1950 e influenciado pela cultura negra dos guetos americanos, quando chegou junto com os imigrantes caribenhos, para se unir aos demais elementos do Hip-hop no período pósguerra (SILVA, 1999). O rap dentro da cultura juvenil em questão teve início com o Mc se limitando a empolgar as pessoas, enquanto o Dj tocava o som. Com o passar do 
tempo, as rimas foram ficando mais elaboradas e mais complexas, fatores decisivos para arrancar aplausos da multidão (VENTURA, s.d.).

Embora o Rap tenha sido aderido pelo mercado fonográfico, a sua prática enquanto arte de rua consistia em desafios improvisados, sem escrita ou elaboração prévia. Desta forma, a modalidade de Rap que abordaremos nesse estudo é o Rap de improviso, espécie de poesia oral baseada no desafio e improviso, mecanismo parecido com o encontrado no Repente. Aqueles que fazem Rap de improviso se expressam através do canto, com base nas suas vivências e conhecimentos. No momento da criação dos versos "os temas são variados, são de acordo com o local e o ambiente" (BARROS, 2002). O rapper vivencia os fatos históricos, sociais, econômicos e políticos, os quais, através da emoção e da imaginação, recriam esse real em forma de versos (BARROS, 2002).

O canto de improviso é em geral uma manifestação da cultura popular, que pode ser entendida como uma forma de classificar pensamentos e ações das populações mais pobres de uma sociedade, é a cultura da classe desfavorecida, que não detém poder (SANTOS, 1994).

Nas principais capitais do Brasil, principalmente em São Paulo, os desafios de rima acontecem nos espaços públicos da cidade. Organizado por jovens que acreditam no ideal do movimento Hip-hop, as batalhas de Mc`s são duelos entre participantes, cujo objetivo é mostrar ao público presente quem tem a maior capacidade de, em um tempo de aproximadamente 40 segundos, se impor sobre o outro, através da sua técnica e habilidade com o ritmo e com as palavras. A ação do "rimador" utilizar na sua criação fatos que aconteceram recentemente - desde notícias da semana, até a cor da roupa do adversário -, impressiona os olhos de quem comparece para apreciar este tipo de arte, 
que é também um jogo cuja principal ferramenta é a criatividade, o conhecimento e o bom desempenho na retórica.

Este trabalho versará sobre a Batalha Central, evento que acontece mensalmente no centro de Piracicaba/SP em que admiradores da cultura Hip-hop e da música Rap se reúnem para travar duelos de rimas, compartilhar maneiras de pensar e fazer música. Através deste estudo, procuraremos entender de que forma esse tipo de prática pode contribuir para o desenvolvimento da criatividade e criticidade dos jovens participantes.

A relevância deste estudo justifica-se na importância de identificar os pontos fortes do Hip-hop como instrumento de desenvolvimento humano, alertando os olhares de profissionais da Educação Física e demais setores da educação, da relevância que se pode ter a inserção da cultura e movimento de rua na educação de crianças e jovens, seja através de meios formais, informais ou não formais.

No caderno do aluno, material didático utilizado por alunos e professores da rede estadual de São Paulo, pode-se encontrar no volume da $8^{\mathrm{a}}$. Série $/ 9^{\circ}$. ano, na disciplina de Educação Física, uma parte dedicada ao Hip-hop. Porém, é notável a necessidade do tema ser aprofundado para poder ser melhor explorado no ambiente educacional, tanto pelo professor como o pelo aluno, que muitas vezes já traz alguma vivência do seu próprio bairro.

É importante ressaltar que não temos a intenção de mostrar a cultura Hip-hop como a solução, mas sim, uma possibilidade a mais para jovens que não dispõem de muitos recursos, bem como uma possibilidade de instrumento educacional para educadores de instituições escolares e não escolares.

Quando nos referimos ao Hip-hop enquanto cultura, é no seu sentido mais amplo, considerando aqui cultura como um conjunto complexo composto de atributos 
como conhecimento, crenças, arte, moral, direito, costumes e outros hábitos e capacidades adquiridas - de maneira não biológica - por membros que integram um determinado grupo social ou sociedade. É a totalidade da vida social do homem caracterizada pela dimensão coletiva, cada cultura é dotada de um "estilo" ou "espírito" particular que influi sobre o comportamento dos indivíduos (CUCHE, 1999).

\section{Objetivos}

Verificar se o Hip-hop (especificamente o Rap de improviso) pode ou não contribuir para o desenvolvimento de um lazer crítico e criativo do individuo participante, além de verificar a influência de ordem moral e cultural que os preceitos do Hip-hop podem exercer sobre o mesmo.

\section{Metodologia}

A presente pesquisa foi realizada num grupo específico denominado Batalha Central, evento juvenil que começou ocorrendo semanalmente na praça José Bonifácio, centro da cidade de Piracicaba/SP, mais precisamente em Junho de 2009. Nesse encontro unem-se tanto aqueles que fazem Rap, ou qualquer outra expressão musical, como os apreciadores, que aparecem no intuito de prestigiar e se divertir.

É uma pesquisa de natureza qualitativa caracterizada por ser um estudo de caso e exploratório. A pesquisa exploratória tem o intuito de "desenvolver, esclarecer e modificar conceitos e ideias, tendo em vista, a formulação de problemas mais precisos ou hipóteses pesquisáveis para estudos posteriores". O presente modelo de pesquisa também é viável devido ao fato de envolver "levantamento bibliográfico, documental e 
entrevistas não padronizadas" elementos estes cabíveis de acordo com o propósito do estudo (GIL, 1999, p43).

Para a obtenção de dados, foram usadas à entrevista semiestruturada, análise documental (vídeos e áudios gravados durante o evento já existentes) e observação participante. A entrevista seria uma forma de conhecer melhor e individualmente alguns integrantes do grupo, já a analise documental segundo Triviños (1987, p111), "fornece ao investigador a possibilidade de reunir uma grande quantidade de informação”.

A execução de um levantamento bibliográfico é fundamental para a eficácia do processo.

Após a coleta, os dados foram organizados e divididos de acordo com tendências e padrões neles identificados. Numa segunda instância os padrões foram reavaliados, buscando relações e inferências num nível de abstração mais elevado (LUDKE e ANDRÉ, 1986).

Para analisar os conteúdos, a separação das unidades de significados geraram os eixos, facilitando a criação de categorias descritivas.

\section{Resultados}

Na Batalha Central reúnem-se aqueles que fazem Rap, assim como os que exercem qualquer outra expressão musical. Um fator primordial nesse tipo de encontro é o público, que aprecia e motiva os artistas, atuando como uma espécie de "combustível" do evento. As pessoas vão chegando ao ponto de encontro pouco a pouco. Enquanto esperam o início, vão conversando assuntos diversos e ouvindo música em seus aparelhos celulares. Entre os diálogos, são comuns as conversas sobre as novidades no cenário musical, principalmente no Rap nacional. Conforme o número de 
participantes e admiradores vai aumentando, é dado inicio a uma espécie de aquecimento cujo rimador vai elaborando suas rimas de improviso. Não há limite de tempo específico, sendo o mesmo determinado pelo período que ele consegue, usufruindo de rimas criativas, manter a plateia entretida.

Quando o rimador que está versando no momento começa a perder a capacidade, ele anuncia o próximo a rimar, que por sua vez passará a assumir a função, dando continuidade ao aquecimento.

O aquecimento não tem um tema específico. Os improvisadores vão versando sobre o que vem a tona no pensamento, com uma mescla de versos relativos ao que se passa no local naquele determinado momento. Pode ser a cor da roupa de alguém, algum fato que se sucedeu ali no ambiente ou algo que estava sendo conversado no local.

Enquanto tudo isso vai acontecendo o organizador e apresentador " $R$ " começa a coletar o nome dos participantes da noite. Em geral, na frente de cada nome é colocado um número, iniciando do "1" seguindo assim na ordem crescente até chegar no nome do último inscrito. Seguidamente solicita-se que cada espectador diga um número, até a chave se formar, por exemplo: se os dois primeiros números ditos pelos espectadores forem três e cinco, o rimador, cujo nome contém o número três na frente batalhará com o rimador de número cinco. O organizador vai pedindo aleatoriamente para o público ir dizendo os números, até que o organograma esteja completo. A chave se assemelha a de um campeonato de uma competição esportiva qualquer. Feito isso, a batalha em si tem início.

Quando prontos para iniciar, os dois rimadores da vez posicionam-se um de frente para o outro enquanto os apreciadores se organizam em volta formando um 
círculo. Geralmente a roda se dá de forma espontânea, no momento em que o inicio da batalha é anunciado. Quando as pessoas estão tímidas ou inibidas, o apresentador estimula.

Tudo pronto para o início, só falta decidir quem começa! Os Mc`s decidem no par ou impar. Quem ganha escolhe se quer começar ou se deixa o outro fazê-lo.

Na maioria das vezes quem ganha no par ou impar prefere que o adversário dê início, tendo assim a opção de responder a provocação iniciada pela outro.

Os duelos entre os Mc`s tem um tempo cronometrado que pode variar de 30 a 40 segundos, de acordo com o critério da organização. Este tempo passa a ser validado a partir do momento em que o rimador inicia seus versos. Em geral o apresentador conta com dois auxiliares voluntários, podendo ser uma pessoa do público ou mesmo um competidor que esteja no aguardo do seu momento de batalhar ou já tenha batalhado. Enquanto um auxiliar fica no controle do tempo, o outro fica no comando de algum aparelho portátil de som (mp4,5,6.., celular, notebook, etc) tocando, pausando e selecionando as bases instrumentais de Rap.

Essas bases instrumentais, desde o início do Hip-hop até hoje, são em linhas gerais, clássicos da música negra norte-americana - Soul, Original Funk, Disco, Jazz, Blues, R\&b etc - mixados novamente pelos $\mathrm{Dj}$ s, acrescidos de batidas mais graves e efeitos, para o interlocutor (Rapper/Mc) fazer a sua rima. Geralmente são musicas evidentes nas paradas de sucesso das rádios no momento em que surgia o Hip-hop. É a verdadeira apropriação e ressignificação da cultura vigente pela cultura popular:

[...] se uma cultura popular é obrigada a funcionar, ao menos em parte, como cultura dominada, no sentido em que os indivíduos dominados devem sempre "viver com" o que os dominantes lhe impõem ou lhe recusam, isto não impede que ela seja uma cultura inteira, baseada em valores e práticas originais que dão sentido à sua existência (CUCHE, 1999). 
Um dos grandes chamarizes desse tipo de evento é a adequação do espaço e do momento para se expor ideias, bem como conhecer ideias de outras pessoas que também participam. Aos que não disputam, porém gostam de expor suas ideias, no final da competição é reservado um tempo para que possam declamar seus poemas, textos, letras de músicas, etc. Tal momento é chamado de Rapoesia.

Além de um momento de lazer, no dia e na hora em que há a Batalha Central, aquele determinado espaço da praça José Bonifácio se torna um ponto de encontro onde jovens de interesses em comum se reúnem para, além de improvisar, trocar informações entre pessoas que compartilham de interesses em comum, seja antes dos duelos de rimas propriamente dito, durante, ou após, quando entre um "tchau" daqui e um "falou" dali, diálogos sobre cds, eventos, livros, programas da tv, entre outras coisas, são comuns. Pessoas trocam cds, dvds, combinam atividades fora da batalha, e muitos acabam se juntando fora dela para produzir arte. Dentro da batalha já aconteceu a formação de alguns grupos musicais.

A transmissão e o recebimento de informação parece ser um dos focos principais, até mesmo fora dela. Os participantes entrevistados afirmam buscar informações em livros, revistas e dicionários de diversos tipos a fim de aprimorar suas rimas de improviso. Pesquisar na internet por vídeos de outras batalhas de Mcs em outros lugares do Brasil, bem como utilizar sites de busca para baixar músicas de estilos diversos para aprimorar a prática, também acontece entre os participantes. Até técnicas de memorização são cogitadas, tudo para melhorar o desempenho no confronto verbal.

O evento acaba tendo um caráter também educativo, ressaltando que falamos em educação para além da escola, considerando a forte influência e interatividade com a 
sociedade e a cultura, interatividade esta, capaz de gerar ideias, valores e modos de interpretar a vida (AGUIAR, 1999).

O público do duelo em questão é bem divido entre masculino e feminino, e embora o Rap seja uma arte predominantemente afrodescendentes, os frequentadores são de grupos étnicos bem diversos. A idade varia geralmente entre 15 e 25 anos de idade, porém a presença de criança e pessoas de meia idade é comum. Os participantes relatam que pessoas de cidades vizinhas, como Santa Bárbara, Americana, Águas de São Pedro, Rio Claro e Limeira, aparecem ocasionalmente para duelar. Alguns jovens estrangeiros que estavam de passagem pela cidade por motivos de passeio ou estudo, também já participaram. O evento já recebeu pessoas de Cabo Verde e dos Estados Unidos.

Muitas pessoas que estão de passagem pelos arredores resolvem parar para prestigiar e entender o que está acontecendo. Segundo os organizadores, o fato do evento ser realizado num espaço público, sem a utilização de grandes recursos, é uma maneira de retomar as raízes do Hip-hop e consequentemente do Rap: a rua e o espaço público.

As praças e parques foram referências importantes para os muitos movimentos da contracultura. Esses espaços públicos abrigavam diversos segmentos sociais, entre eles burgueses conservadores, hippies, grupos de negros, criança, policiais, etc. A importância desses espaços se dava pelo fato de servirem como palco do encontro entre as diferenças, consequentemente trazendo junto dos encontros conflito, segregação, cooperação, aprendizado, tolerância, hostilidade, descoberta, e entre tudo isso, o favorecimento à diversidade e a coletividade (ALBUQUERQUE, 2009). 
Os eventos de Hip-hop - isso antes mesmo de ser denominado como tal também aconteciam em espaços públicos e eram marcados pela presença de uma vasta diversidade de pessoas, não ficando os eventos limitados apenas à população negra e pobre. Os eventuais encontros eram abertos para diferentes grupos que se identificavam com aquela manifestação. Praticamente contemporâneo da contracultura, o Hip-hop teria como objetivo transformar o negativo em positivo, num esforço de potencializar o talento dos jovens pobres e suburbanos através de novas formas de expressão artística (PIRES, 2007)

Os guetos de Nova Iorque dos anos 60/70 foram o local do surgimento de contingentes juvenis não-brancos reunindo-se para falar, cantar, desenhar e dançar suas criações a partir dos resíduos tecnológicos da cidade e de suas experiências de vida. (CORNIANI, 2002, p. 5).

Contribuir para uma postura mais crítica e criativa do jovem, envolvido com as expressões artísticas do Hip-hop enquanto cidadão, parecia ser uma das intenções de Afrika Bambaataa e sua fundação, a Zulu Nation, ao pregar além dos quatro elementos convencionais do Hip-hop, o quinto elemento, considerado como a base para os outros: o conhecimento. Segundo Souza e Nista - Piccolo, (2006) Bambaataa visava o fim dos conflitos entre jovens residentes nos arredores do Bronx. Para ele, uma das formas de minimizar tais conflitos, era fazer com que estes jovens buscassem a conscientização da realidade que os rodeavam, sendo assim, "por intermédio de atividades culturais e artísticas, os jovens seriam levados a refletir sobre sua realidade e a tentar a partir de então transformá-la" (ROCHA ${ }^{4}$ et al., 2001, p. 18-19 apud FIALHO, 2003, p. 21).

\footnotetext{
${ }^{4}$ ROCHA, Janaina; DOMENICH, Mirella; CASSEANO, Patrícia. Hip Hop - a periferia grita. São Paulo: Fundação Perseu Abramo, 2001.
} 
Segundo Andrade ${ }^{5}$ (1999) citado por Fialho (2003), o interesse na difusão Hiphop pelos seus praticantes está ligado ao fato do mesmo ser um movimento social que “permite aos jovens desenvolver uma educação política e, consequentemente, o exercício do direito à cidadania”.

\section{Conclusão}

Através deste estudo, foi possível perceber a influência exercida pelos preceitos do Hip-hop na vida dos jovens que participam desta prática, prática esta que acaba suprindo algumas necessidades em um determinado momento reservado para o lazer, necessidades estas provavelmente não satisfeitas na escola, ou em outro seguimento da sociedade. O que notamos é que os duelos mensais de improviso, além de, primeiramente serem uma busca por um lazer gratuito, em um tempo em que se divertir é quase sinônimo de pagar caro para tal, a Batalha Central acaba sendo um espaço para se buscar um determinado tipo de informação, é uma busca também pelo desenvolvimento pessoal e pela cidadania, além é claro, de ser uma oportunidade de se expressar e exercitar a comunicação com o outro, sem constrangimentos.

É comum no contato com estes jovens, notar que a busca pela informação faz parte da rotina deles enquanto participantes de duelos de rimas. Muitos que começaram através das batalhas, ouvindo os Raps mais evidentes na mídia, passaram a pesquisar os Raps menos evidentes e até a pesquisar outros estilos musicais.

A busca pela informação e o compartilhamento da mesma, nos dias de duelo, acaba trazendo uma maneira a mais de pensar, talvez uma maneira não encontrada na família, na escola ou no trabalho.

${ }^{5}$ ANDRADE, E. N. A. (Org.) Rap e educação, rap é educação. São Paulo: Summus, 1999. 
A criticidade aguçada desses jovens aparece dentro da própria cultura Hip-hop, pois são jovens que não concordam e não gostam, na sua maioria, dos Raps que aparecem nos grandes meios de comunicação, estão sempre buscando artistas e músicas fora deste circuito, em geral valorizam os artistas locais e tem como lema a expressão "faça você mesmo", criam suas festas, sua arte, além de usarem a criatividade para divulgar seus trabalhos e eventos ligados à cultura. A forma mais utilizada pelos participantes para divulgar a Batalha Central são as redes sociais na internet: Facebook, Orkut e Twitter. Os vídeos no site Youtube, como amostra das edições que já ocorreram, chamam a atenção do púbico novo que se sente instigado a ir conferir ao vivo como tudo funciona.

Muitos desses jovens relatam utilizar o aprendizado da batalha no dia-a-dia, de modo a serem mais proativos, quando precisam de uma informação, ou até mesmo de ler um jornal ou ver um programa de televisão com uma visão mais crítica e questionadora. Os preceitos do Hip-hop criados por Afrika Bambaataa também fazem parte do cotidiano destes jovens, segundo o relato deles, no que diz respeito a buscar a melhor maneira de resolver conflitos, buscar o conhecimento e a consciência.

Não é difícil notar a presença dos Raps e outros elementos do movimento cultural Hip-hop dentro da escola, porém, por falta de conhecimento, muitas vezes nós, professores, tratamos o Hip-hop primeiramente enquanto "dança da periferia" considerando muito mais a sua beleza estética e o seu caráter de divertimento, não considerando os valores que este movimento pode agregar na vida dos seus participantes enquanto um estilo de vida.

Buscar conhecer como essas expressões artísticas, políticas e culturais cheias de significados e carregados de contexto histórico interferem na vida dos jovens 
participantes desta cultura, pode facilitar e ampliar o trabalho de nós professores para com os alunos, tal como pode nos dar um respaldo mais concreto do que temos hoje, nas cartilhas escolares, que acabam tratando o Hip-hop a partir de um ponto de vista simplista. A compreensão ampliada do professor não só do Hip-hop, mas das diversas culturas juvenis que possam existir, pode contribuir para o estreitamento da relação professor-aluno, facilitando e melhorando as relações.

Neste estudo, pudemos constatar e entender um pouco de como especificamente as batalhas de Mc`s interferem no desenvolvimento da criatividade e criticidade do praticante e como esse momento de lazer pode contribuir para o desenvolvimento do jovem e a sua busca de identidade e cidadania. Ainda assim, são necessários estudos mais aprofundados que possam contar com a contribuição de diversas áreas do conhecimento para entender melhor essa manifestação cultural que segue desde os anos 80 até a atualidade, presente nas periferias, centros comunitários e escolas do mundo todo.

\section{REFERÊNCIAS}

AGUIAR, C. M. Procedimentos lúdicos e cultura. Revista Motriz, Rio Claro: v. 5, n. 1, p. 22-27, 1999.

ALBUQUERQUE, Leila M. B. Hair. "Paz e amor!". Revista Nures, v. 5, n.12, mão/agosto, 2009. Disponível em: www.pucsp.br/revistanures.

ANDRADE, E. N. A. (Org.) Rap e educação, rap é educação. São Paulo: Summus, 1999.

BAHIA, Mirleide Chaar. Lazer - Meio Ambiente: em busca das atitudes vivenciadas nos esportes de aventura. 2005. 113p. Dissertação (Mestrado) - Educação Física. Universidade Metodista de Piracicaba, Piracicaba, 2005.

BARROS, M. L. A. A literatura popular para além da Modernidade. Anuário de literatura, Florianópolis, n. 10, 2002. 
BRUHNS, H. T. Relações entre a educação e o lazer. In: BRUHNS, H. T. (Org.). Introdução aos estudos do lazer. Campinas: Ed Unicamp, 1997. p. 33-55.

CAPI, André Henrique Chabaribery. Lazer e esporte nos clubes social-recreativos de Araraquara. 2006. 109p. Dissertação (Mestrado em Educação Física) Universidade Metodista de Piracicaba, Piracicaba, 2006.

CORNIANI, Fábio Rodrigues. Rap: Manifestação popular urbana. INTERCOM sociedade Brasileira de Estudos Interdisciplinares da Comunicação. CONGRESSO BRASILEIRO DE CIÊNCIAS DA COMUNICAÇÃO, 25. Salvador. Anais... 1 a 5 set, 2002.

CUCHE, Denys. A noção de cultura nas ciências sociais. Bauru: Edusc, 1999.

FIALHO, Vânia A. Malagutti da Silva. Hip hop sul: um espaço televisivo de formação e atuação musical. 2003. 186p. Dissertação (Mestrado em Música) - Universidade Federal do Rio Grande do Sul, Porto Alegre - Rio Grande do Sul, 2003.

GIL, Antônio Carlos. Métodos e técnicas de pesquisa social. 5. ed. São Paulo: Atlas, 1999.

LUDKE, Menga; ANDRÉ, Marli E. D. A. Pesquisa em educação: abordagens qualitativas. São Paulo: EPU, 1986.

MARCELLINO, Nelson Carvalho. Estudos do lazer: uma introdução. 3. ed. Campinas: Autores Associados, 2002.

PIRES, João Rodrigo Xavier. Da tropicália ao hip-hop: contracultura, repressão e alguns diálogos possíveis. 2007. 62p (Trabalho de conclusão de curso) - Departamento de História. Rio: PUC, 2007.

ROCHA, Janaina; DOMENICH, Mirella; CASSEANO, Patrícia. Hip Hop - a periferia grita. São Paulo: Fundação Perseu Abramo, 2001.

ROSA, Celso Martins. Cultura rap nas conexões das linguagens artísticas. In: Arte em Pesquisa: especificidades / Anpap, 2004, Brasília. Questões do corpo e da cena. Brasília: Pós-Graduação em Artes da Universidade de Brasília / Anpap, 2004. v.1 p. 384-291.

SANTOS, Vanusa Mascarenhas. Literatura oral e cultura popular: passando em revista velhos temas. In: ENCONTRO BAIANO DE ESTUDOS EM CULTURA, 1, Salvador. Anais... 2008.

SANTOS, José Luiz dos. O que é cultura. 14. ed. São Paulo: Brasiliense, 1994.

SILVA, J. C. G. Arte e educação: a experiência do movimento hip-hop paulistano. In: ANDRADE, E. N. A. (Org.) Rap e educação, rap é educação. São Paulo: Summus, 1999, cap. 2, p. 23-38. 
SOUZA, I. C.; NISTA-PICCOLO, V. L. Hip Hop e Educação Física Escolar: Possibilidades de Novas Tematizações. In: CONGRESSO BRASILEIRO CIENTÍFICO POPULAR DE EDUCAÇÃO FÍSICA CAEF FCT/ UNESP, 1. Anais... UNESP, 2006.

STOPPA, Edmur Antonio. "Ta ligado mano": o hip-hop como lazer e busca da cidadania. 2005. 143p. Tese (Doutorado em Educação Física) - Universidade Estadual de Campinas, Campinas, 2005.

TRIVIÑOS, Augusto Nibaldo Silva. Introdução à pesquisa em ciências sociais: a pesquisa qualitativa em educação. São Paulo: Atlas, 1987.

VENTURA, Bruno. História da Cultura Hip Hop. Overmundo, [s.d.]. Disponível em: $<$ http://www.overmundo.com.br/overblog/historia-da-cultura-hip-hop $>$ Acesso em: 14 mai 2011.

\section{Endereço dos Autores:}

Daniel Bidia O. Tejera

Carmem Maria Aguiar

Universidade Estadual Paulista "Júlio de Mesquita Filho"

Instituto de Biociências - Departamento de Educação Física

Avenida 24-A, número 1515 - CEP: 13506-900 - Rio Claro/SP

Endereço Eletrônico: olmedo@ig.com.br 